\title{
Effect of Vitamin D on Canine Distalization and Alveolar Bone Density Using Multi-slice Spiral CT: A Randomized Controlled Trial
}

\author{
Sanju T Varughese ${ }^{1}$, Pavithra U Shamanna ${ }^{2}$, Neeraj Goyal ${ }^{3}$, Beenu S Thomas ${ }^{4}$, Lakshmi Lakshmanan ${ }^{5}$, Venith J Pulikkottil ${ }^{6}$, \\ Mohammed G Ahmed ${ }^{7}$
}

\begin{abstract}
Aim: The aim of this split-mouth, blinded randomized controlled trial was to evaluate the clinical and radiographic effects of locally delivered 1,25 dihydroxycholecalciferol $(1,25 \mathrm{DHC})$ on the amount of canine distalization.

Materials and methods: Fifteen patients between age groups of 15 years to 30 years willing to undergo orthodontic treatment in a dental college participated in the study. A computer-generated randomization list was generated to divide the maxillary arch into experimental side and control side. Allocation concealment was applied. Canine distalization was initiated using nickel-titanium (NiTi) closed coil springs delivering a force of $150 \mathrm{~g}$ per side, which was attached to the maxillary first molar tube and canine hook. Local periodontal gel injection of 1,25 DHC was given on the experimental side and placebo gel on the control side at distal side of the maxillary canine at monthly interval, respectively. Patients were evaluated from beginning $\left(T_{0}\right)$, 4 weeks $\left(T_{1}\right)$, 8 weeks $\left(T_{2}\right)$, and 12 weeks $\left(T_{3}\right)$. CT scans were taken at $T_{0}$ and $T_{3}$ to measure the changes in bone density. The difference in amount of canine distalization and the changes in bone density were assessed on the experimental and control sides, respectively. Descriptive statistics and paired $t$ test were used to determine any differences.

Results: The results showed statistically significant increase in the amount of canine distalization and decrease in cancellous bone density on the experimental side when compared to control side.
\end{abstract}

Conclusion: The active form of vitamin D can be an effective agent to accelerate orthodontic tooth movement (OTM).

Clinical significance: This study provides a new insight into the scope of vitamin D in clinical orthodontics and its innovative method of application to accelerate tooth movement in patients will revolutionize treatment as well as open newer boundaries in orthodontic research at a biomolecular level.

Keywords: Bone density, Canine distalization, Randomized controlled trial, Vitamin D.

The Journal of Contemporary Dental Practice (2019): 10.5005/jp-journals-10024-2698

\section{INTRODUCTION}

A variety of medications and nutritional supplements are available that may accelerate or inhibit tooth movement. ${ }^{1}$ Orthodontic tooth movement ( OTM) is triggered by prolonged application of controlled mechanical forces. Various cell-signaling pathways are activated leading to increased metabolism of periodontal ligament which results in localized bone resorption and deposition. ${ }^{2,3}$ With the emerging concept of "accelerated orthodontics," scientific interest has been focused on chemical ${ }^{4,5}$ and electrical ${ }^{6}$ stimuli in combination with mechanical forces for rapid bone turnover and more stable results. Most attempts can broadly be categorized into biological, physical, biomechanical, and surgical approaches. Studies have attempted to use biomolecules such as prostaglandin E (PGE), cytokines, and receptor activator of nuclear factor kappa-B ligand (RANKL), etc., exogenously to enhance OTM by inducing changes in the morphology of osteoclasts and osteoblasts through increased intracellular production of cyclic AMP, mRNA synthesis, and protein secretion of RANKL. ${ }^{7,8}$

The active form of vitamin D 1,25-dihydroxycholecalciferol (hence referred to as 1,25 DHC) is a potent stimulator of osteoclastic activity by inducing differentiation of osteoclast precursors as well as increasing the activity of existing osteoclasts. It is also known to stimulate osteoblastic cell differentiation and bone mineralization in a dose-dependent manner. It has plasma half-life of 2-3 hours, but its cellular effects may last for several days. Agents that enhance OTM may aid in reducing the treatment time by faster
1,5,6 Department of Orthodontics and Dentofacial Orthopedics, Malabar Dental College and Research Centre, Edappal, Kerala, India

${ }^{2}$ Department of Orthodontics and Dentofacial Orthopedics, Sri Hasanamba Dental College and Hospital, Hassan, Karnataka, India

${ }^{3}$ Dental Department, Panchkula Welfare Trust, Panchkula, Haryana, India

${ }^{4}$ Department of Prosthodontics, Malabar Dental College and Research Centre, Edappal, Kerala, India

${ }^{7}$ Department of Pharmacology, Yenepoya College of Pharmacy and Research Centre, Yenepoya University, Mangaluru, Karnataka, India

Corresponding Author: Sanju T Varughese, Department of Orthodontics and Dentofacial Orthopedics, Malabar Dental College and Research Centre, Edappal, Kerala, India, Phone: +91 9847372051 , e-mail: santhoms18@gmail.com

How to cite this article: Varughese ST, Shamanna PU, Goyal N, et al. Effect of Vitamin D on Canine Distalization and Alveolar Bone Density Using Multi-slice Spiral CT: A Randomized Controlled Trial. J Contemp Dent Pract 2019;20(12):1430-1435.

Source of support: Nil

Conflict of interest: None

space closure. Agents that inhibit tooth movement (increased bone mineralization) may increase the stability after active treatment has concluded or even improve the anchorage capacity of a tooth.

(0) The Author(s). 2019 Open Access This article is distributed under the terms of the Creative Commons Attribution 4.0 International License (https://creativecommons. org/licenses/by-nc/4.0/), which permits unrestricted use, distribution, and non-commercial reproduction in any medium, provided you give appropriate credit to the original author(s) and the source, provide a link to the Creative Commons license, and indicate if changes were made. The Creative Commons Public Domain Dedication waiver (http://creativecommons.org/publicdomain/zero/1.0/) applies to the data made available in this article, unless otherwise stated. 
$1,25 \mathrm{DHC}$ can produce both effects depending upon the dose. It is involved in the formation of osteoclasts from precursor monocytes and may produce these effects at much lower doses than other hormones such as prostaglandins. ${ }^{4,9}$ The effect of vitamin D on the alveolar bone density was evaluated quantitatively using low-dose multi-slice spiral CT which can yield accurate value measurement in Hounsfield units (HU). ${ }^{10}$ The aim of this study was to understand the clinical and radiographic effects of locally delivered 1,25 DHC on the amount of canine distalization.

\section{Materials and Methods}

\section{Trial Design}

This was a split-mouth, blinded, prospective, single-center randomized controlled trial with 1:1 allocation ratio.

\section{Registration}

Registered at Clinical Trials Registry India (CTRI/2017/06/008902).

\section{Participants, Eligibility Criteria, and Settings}

Fifteen healthy patients willing to undergo orthodontic treatment at the Department of Orthodontic and Dentofacial Orthopedics, Sri Hasanamba Dental College and Hospital, Hassan, were recruited as study participants. The study was approved by the Ethical Committee board before patient recruitment. Inclusion criteria were the following: (1) age groups of 15-30 years, (2) average skeletal pattern, (3) angle's class I or class II dental malocclusion indicated for bilateral maxillary first premolar extraction, and (4) minimum $5 \mathrm{~mm}$ of extraction space. Exclusion criteria include (1) previous history of orthodontic or orthopedic treatment; (2) presence of craniofacial anomalies; (3) presence of any signs and symptoms of gingival and periodontal diseases; (4) presence of significant medical history (including drug allergy), and (5) pregnant and lactating women. Written consent was taken from all the participants.

\section{Randomization (Random Number Generation, Allocation Concealment, and Implementation)}

For every participant, the maxillary arch was randomized into experimental and control sides using a computer-generated randomization list. Allocation concealment was achieved with sequentially numbered and sealed envelopes.

\section{Blinding}

The operators and study participants were blind about experimental and control sides. The seventh author was involved in gel preparations. The injections were performed by first author who was also blind about the type of injection (1,25 DHC or placebo gel). The third and sixth authors measured the force for canine distalization. The fourth author assisted multi-slice computed tomography (MSCT) scans at the region of interest. Second and fifth authors were blinded during data analyses.

\section{Interventions}

All participants were bonded with $0.022 \times 0.028$ inch slot brackets (Ortho Organisers, Inc., USA) using pre-adjusted edgewise appliance with $0.022 \mathrm{MBT}$ prescriptions. Following the extraction of maxillary first premolars, initial leveling and alignment were achieved utilizing continuous NiTi (Prime Orthodontics, Inc., Portland, USA) archwire sequencing. Then $0.019 \times 0.025$ inch stainless steel archwires (Prime Orthodontics, Inc., Portland, USA) were left in situ for 4 weeks to obtain standardized first, second, and third order prescriptions.
The maxillary arch impressions were made using alginate (Algitex DPI) at the end of leveling and aligning to obtain study models. Canine distalization was initiated using NiTi closed coil springs delivering a force of $150 \mathrm{~g}$ per side, which was attached to the maxillary first molar tube and canine hook, measured using measuring gauge (Correx, Haag-Streit International). The anchorage system included bilateral 2nd molar banding with transpalatal bar. At each appointment, oral hygiene measures were reinforced.

\section{1,25 DHC Gel Administration Protocol}

During the course of the trial, participants were instructed to take acetaminophen as the only analgesic for relief of orthodontic treatment related pain. The injection was delivered using a disposable 30-gauge needle and syringe. A dose of $50 \mathrm{pg}$ per $0.2 \mathrm{~mL}$ of calcitriol (1,25 DHC) periodontal (intraligamentary) injection was given on the experimental side, as shown in Figure 1, and $0.2 \mathrm{~mL}$ placebo gel (plain gel without calcitriol) injection was given on the control side, in the distal side of canine at monthly intervals, respectively, for duration of three months. Participants were evaluated from the beginning $\left(T_{0}\right), 4$ weeks $\left(T_{1}\right)$, 8 weeks $\left(T_{2}\right)$, and 12 weeks $\left(T_{3}\right)$ of canine distalization. At these appointments, impressions were made to obtain the study models. Multi-slice spiral computed tomography scans were taken at $T_{0}$ and $T_{3}$ to measure the changes in bone density following canine distalization.

The primary outcome was to evaluate the rate and total amount of canine distalization as well as anchorage loss in the maxillary arch. All study measurements were performed on dental casts with stable reference points ${ }^{11}$ using digital vernier caliper. The movement of canine was measured from the canine tip and mesiobuccal groove of maxillary first molar. Measurements were repeated to check for reproducibility. The rate of canine distalization was obtained by calculating the differences between sequential measurements $\left(T_{0}-T_{1}, T_{1}-T_{2}\right.$, and $\left.T_{2}-T_{3}\right)$. The total amount of movement was the difference between $T_{0}$ and $T_{3}$. The mean monthly movement was obtained by dividing the total amount of movement by three (number of evaluations). The molar anchorage loss was measured from mesiobuccal groove of maxillary molar and lateral ends of third palatal rugae. ${ }^{11}$ The secondary outcome was to evaluate the changes in the alveolar bone density (axial section) in the maxillary arch. It was measured in the alveolar bone on the experimental and control sides at the region distal to canine root, at the beginning $\left(B_{O}\right)$

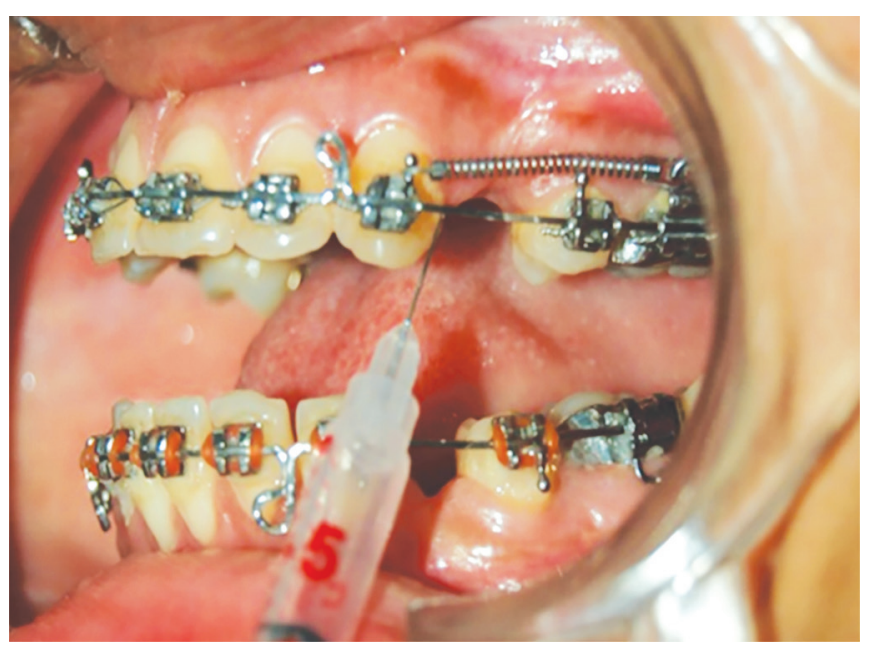

Fig. 1: Local periodontal injection of in situ gel given distal to maxillary canine 
and the 12th week $\left(B_{X}\right)$ of canine distalization. The MSCT (HiSpeed NXI MultiSlice CT system GE Medical system) parameters used were $0^{\circ}$ gantry tilt, high-resolution bone Kernel, $0.5 \mathrm{~mm}$ nominal slice thickness, $120 \mathrm{kV}$, and $120 \mathrm{~mA}$. The measurements were calculated using Advantage Workstation software (AW-Version 4.3) in HU. The CT sections were taken 3-5 mm apical from the alveolar bone crest. At each axial section, the density at the center point ${ }^{12}$ of the buccal cortical bone (BC), cancellous bone (C), and palatal cortical bone (PC) was measured. The density of the cancellous bone was measured at the trabeculae, located halfway buccolingually between the buccal and palatal cortical plates, as illustrated in Figure 2.

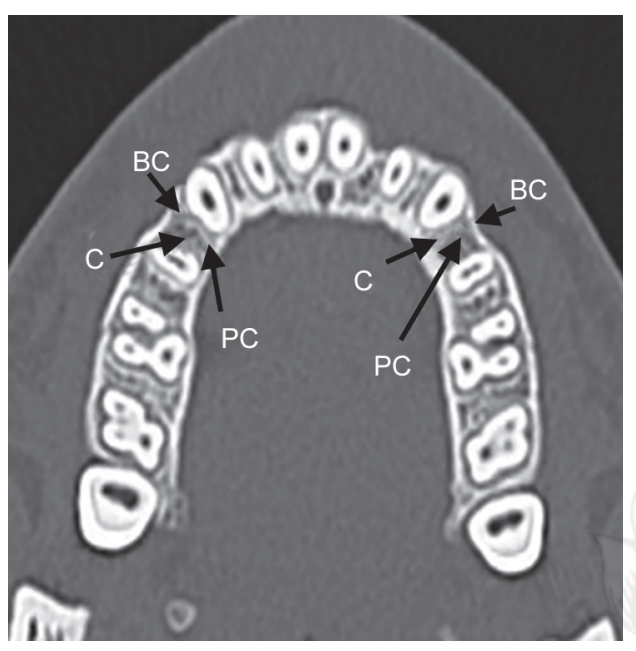

Fig. 2: Alveolar bone density sites to be measured distal to maxillary canine

\section{Interim Analyses and Stopping Guidelines}

No interim analysis was performed during the study and no stopping guidelines were established.

\section{Statistical Analysis}

Data were analyzed by descriptive statistics; paired $t$ test, and independent $t$ test using SPSS software (SPSS Inc., Chicago, Illinois, USA). Statistical significance was set at the 0.05 probability level.

\section{Results \\ Participant Flow}

All 15 patients who were recruited completed the study, as shown in Flowchart 1. The average age was 22.5 year, with a range of 15-30 years.

\section{Comparison of Monthly Amount of Canine Distalization (Table 1 and Fig. 3)}

The mean amount of canine distalization in the first month was $1.5680 \pm 0.36830$ on the experimental side and $1.0260 \pm 0.17727$ on the control side. In the second month, it was $1.7073 \pm 0.33275$ on the experimental side and $1.0787 \pm 0.26295$ on the control side. In the third month, it was $1.1993 \pm 0.28684$ on the experimental side and $0.9367 \pm 0.18321$ on the control side. When the subjects were compared within and between the groups, there was a statistically significant difference at 5\% significance level.

\section{Comparison of Total Amount of Canine Distalization}

Paired $t$ test showed statistically significant difference $(p-0.000)$ between experimental and control sides at a significance level of $1 \%$, over a period of 3 months.

Flowchart 1: Consort flow diagram

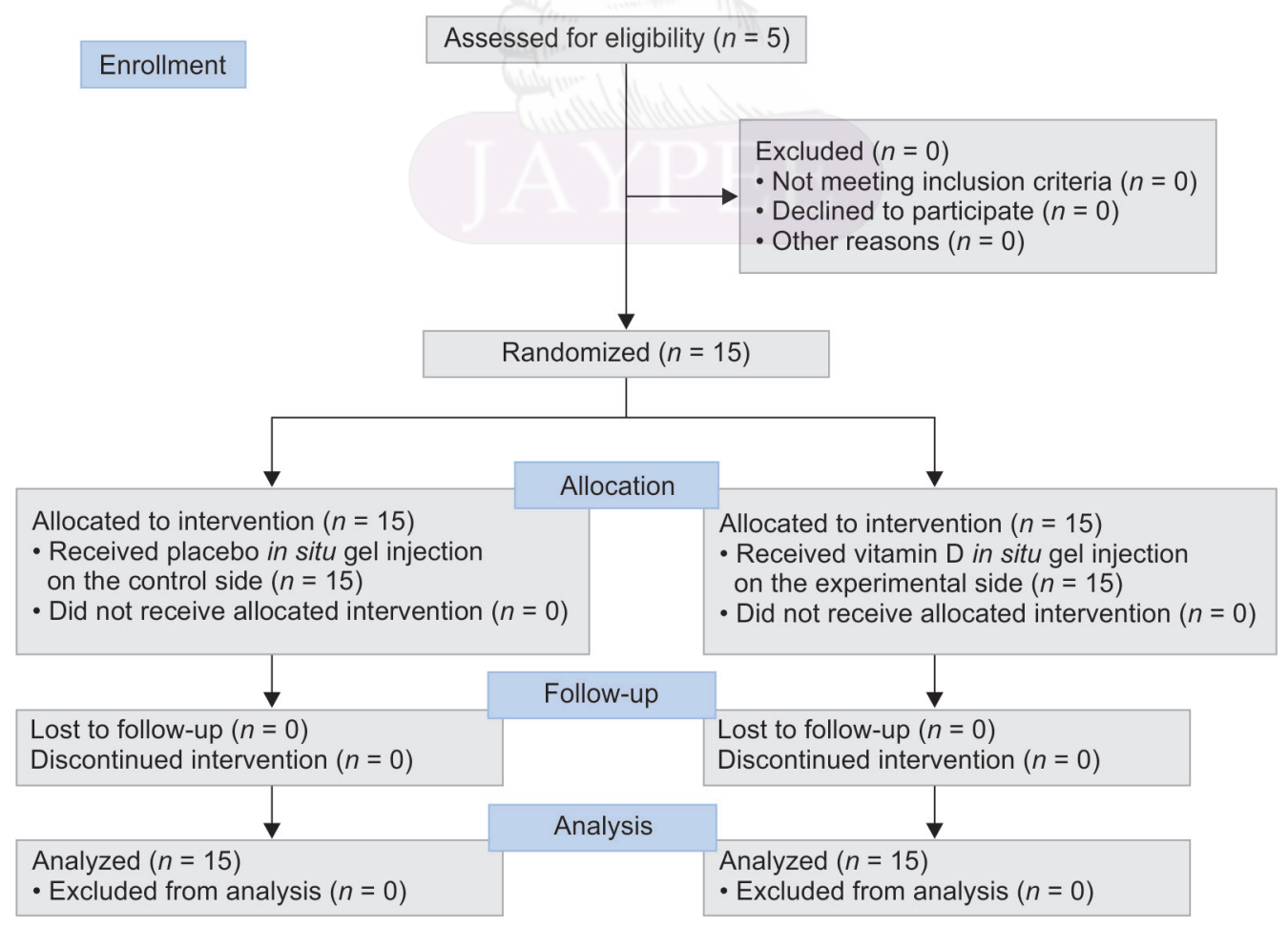




\section{Comparison of Total Anchorage Loss Over a Period of 3 Months (Table 2 and Fig. 4)}

Paired $t$ test showed statistically insignificant $(p-0.769)$ amount of anchorage loss on both the experimental and control sides, over a period of 3 months.

\section{Comparison of the Alveolar Bone Density on the Experimental Side (Table 3)}

Independent $t$ test was applied. Within the experimental side at a significance level of $1 \%$, there was statistically significant difference ( $p$ value -0.000$)$ in the bone density at all the three regions.

Table 1: Comparison of monthly amount of canine distalization

\begin{tabular}{lllll}
\hline & Group & Mean & SD & $n$ \\
\hline $\mathrm{T}_{0}-\mathrm{T}_{1}$ & " $\mathrm{E}$ " side & 1.5680 & 0.36830 & 15 \\
& "CC" side & 1.0260 & 0.17727 & 15 \\
$\mathrm{~T}_{1}-\mathrm{T}_{2}$ & " $\mathrm{E}$ " side & 1.7073 & 0.33275 & 15 \\
& "CC" side & 1.0787 & 0.26295 & 15 \\
$\mathrm{~T}_{2}-\mathrm{T}_{3}$ & "E" side & 1.1993 & 0.28684 & 15 \\
& "CC" side & 0.9367 & 0.18321 & 15 \\
\hline
\end{tabular}

"E", experimental; "C", control

Table 2: Comparison of total anchorage loss over a period of 3 months

\begin{tabular}{|c|c|c|c|c|c|c|c|c|}
\hline Group & & $n$ & Mean & $S D$ & $\begin{array}{l}\text { Standard error } \\
\text { mean }\end{array}$ & $d f$ & $\begin{array}{l}\text { p value } \\
\text { (two-tailed) }\end{array}$ & Significance \\
\hline \multirow[t]{2}{*}{$A_{X}-A_{O}$} & "E" side & 15 & 0.6300 & 0.27581 & 0.07121 & 28 & 0.769 & NS \\
\hline & "C" side & 15 & 0.5993 & 0.28977 & 0.07482 & & & \\
\hline
\end{tabular}

NS, statistically not significant

Table 3: Comparison of the alveolar bone density on the experimental side

\begin{tabular}{|c|c|c|c|c|c|c|c|}
\hline Group & & Mean & $n$ & $S D$ & $\begin{array}{l}\text { Standard error } \\
\text { mean }\end{array}$ & $d f$ & $\begin{array}{l}p \text { value } \\
\text { (two-tailed) }\end{array}$ \\
\hline \multirow[t]{2}{*}{ Pair $1(\mathrm{BC})$} & $\mathrm{B}_{\mathrm{O}}$ & 887.6000 & 15 & 181.90139 & 46.96674 & 14 & $0.001^{*}$ \\
\hline & $\mathrm{B}_{\mathrm{X}}$ & 880.2667 & 15 & 182.17043 & 47.03620 & & \\
\hline \multirow[t]{2}{*}{ Pair 2 (C) } & $\mathrm{B}_{\mathrm{O}}$ & 230.7333 & 15 & 77.22275 & 19.93883 & 14 & $0.000^{*}$ \\
\hline & $B_{x}$ & 210.8000 & 15 & 73.88814 & 19.07784 & & \\
\hline \multirow[t]{2}{*}{ Pair 3 (PC) } & $\mathrm{B}_{\mathrm{O}}$ & 981.6000 & 15 & 187.01902 & 48.28810 & 14 & $0.000^{*}$ \\
\hline & $\mathrm{B}_{\mathrm{X}}$ & 976.2000 & 15 & 186.25911 & 48.09190 & & \\
\hline
\end{tabular}

${ }^{*}$ statistically highly significant $(\mathrm{HS})$

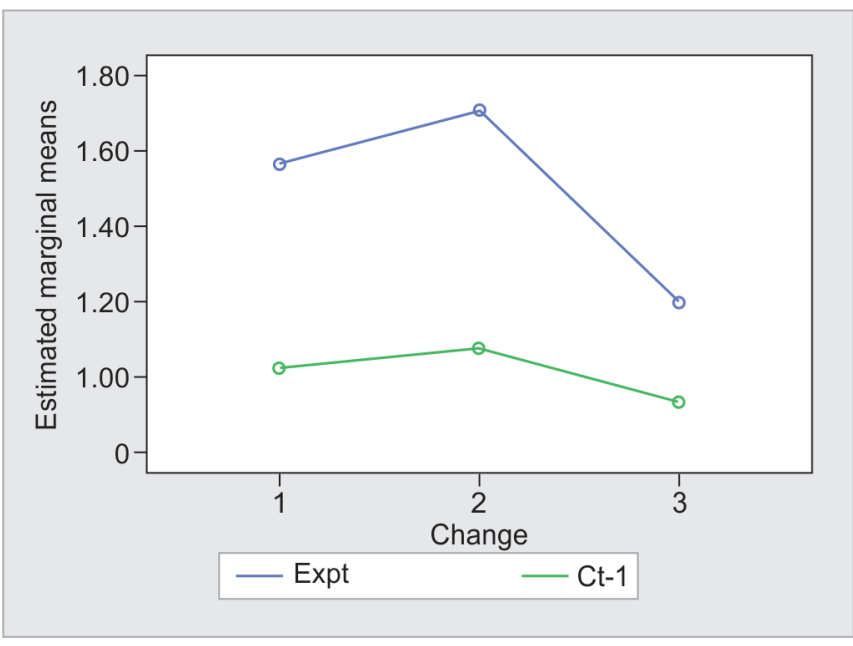

Fig. 3: Mean difference in the monthly amount of canine distalization at 1st month $\left(T_{0}-T_{1}\right)$, 2nd month $\left(T_{1}-T_{2}\right)$, and 3rd month $\left(T_{2}-T_{3}\right)$

\section{Comparison of the Alveolar Bone Density on the Control Side (Table 4)}

Independent $t$ test was applied. Within the control side at a significance level of $1 \%$, there was statistically significant difference ( $p$ value-0.000) in the alveolar bone density at all the three regions.

\section{Comparison of Alveolar Bone Density between Experimental and Control Sides (Table 5 and Fig. 5)}

The bone density was measured using spiral CT on both the experimental and control sides at three regions (buccal cortical, cancellous, and palatal cortical bones). There was statistically insignificant difference ( $p$ value-0.521) in the bone density on the buccal cortical bone between the experimental and control sides. At a significance level of $1 \%$, there was statistically significant difference ( $p$ value-0.000) in the bone density on the cancellous bone between experimental and control sides. There was statistically insignificant difference ( $p$ value-0.649) in the bone density on the palatal cortical bone between experimental and control sides. 
Table 4: Comparison of the alveolar bone density on the control side

\begin{tabular}{|c|c|c|c|c|c|c|c|}
\hline Group & & Mean & $n$ & $S D$ & $\begin{array}{l}\text { Standard error } \\
\text { mean }\end{array}$ & $d f$ & $\begin{array}{l}p \text { value } \\
\text { (two-tailed) }\end{array}$ \\
\hline \multirow[t]{2}{*}{ Pair 1 (BC) } & $\mathrm{B}_{\mathrm{O}}$ & 906.2667 & 15 & 130.12492 & 33.59811 & 14 & $0.000^{*}$ \\
\hline & $\mathrm{B}_{\mathrm{x}}$ & 900.2667 & 15 & 129.68008 & 33.48325 & & \\
\hline \multirow[t]{2}{*}{ Pair 2 (C) } & $\mathrm{B}_{\mathrm{O}}$ & 235.1333 & 15 & 47.85375 & 12.35578 & 14 & $0.000^{*}$ \\
\hline & $\mathrm{B}_{\mathrm{x}}$ & 227.6000 & 15 & 46.80629 & 12.08533 & & \\
\hline \multirow[t]{2}{*}{ Pair 3 (PC) } & $\mathrm{B}_{\mathrm{O}}$ & 984.2000 & 15 & 78.57044 & 20.28680 & 14 & $0.000^{*}$ \\
\hline & $\mathrm{B}_{\mathrm{X}}$ & 979.3333 & 15 & 79.50172 & 20.52726 & & \\
\hline
\end{tabular}

*Statistically highly significant (HS)

Table 5: Comparison of alveolar bone density between experimental and control sides

\begin{tabular}{|c|c|c|c|c|c|c|c|}
\hline Group & & $n$ & Mean & $S D$ & $\begin{array}{l}\text { Standard error } \\
\text { mean }\end{array}$ & $\begin{array}{l}\text { p value } \\
\text { (two-tailed) }\end{array}$ & Significance \\
\hline \multirow[t]{2}{*}{$\mathrm{B}_{\mathrm{X}}-\mathrm{B}_{\mathrm{O}}(\mathrm{BC})$} & "E" side & 15 & 7.3333 & 7.06770 & 1.82487 & 0.521 & NS \\
\hline & "C" side & 15 & 6.0000 & 3.64496 & 0.94112 & & \\
\hline \multirow[t]{2}{*}{$\mathrm{B}_{\mathrm{X}}-\mathrm{B}_{\mathrm{O}}(\mathrm{C})$} & "E" side & 15 & 19.9333 & 9.77947 & 2.52505 & $0.000^{*}$ & $\mathrm{HS}$ \\
\hline & "C" side & 15 & 7.5333 & 3.35659 & 0.86667 & & \\
\hline \multirow[t]{2}{*}{$\mathrm{B}_{\mathrm{X}}-\mathrm{B}_{\mathrm{O}}(\mathrm{PC})$} & "E" side & 15 & 5.4000 & 2.32379 & 0.60000 & 0.649 & NS \\
\hline & "C" side & 15 & 4.8667 & 3.83344 & 0.98979 & & \\
\hline
\end{tabular}

*Statistically highly significant (HS); NS, statistically not significant

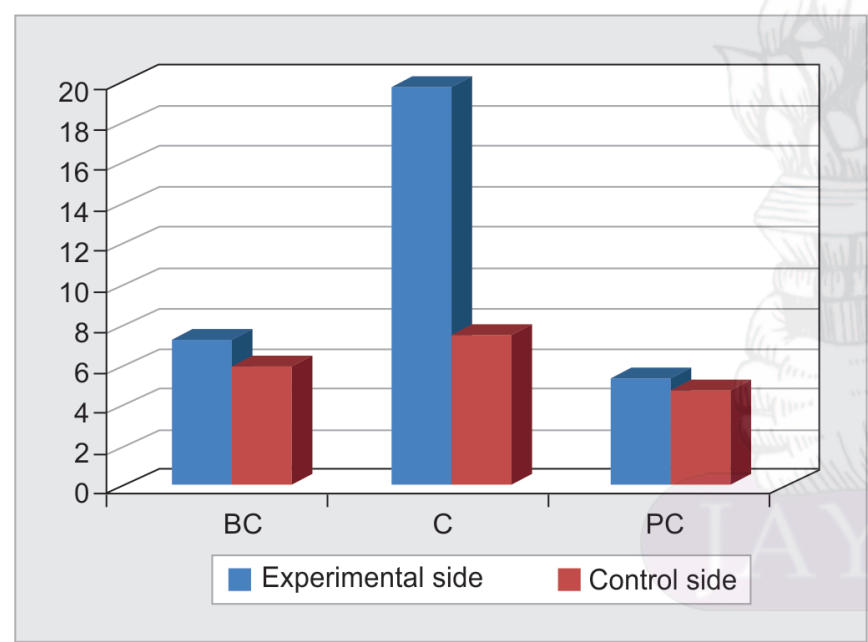

Fig. 5: Comparison of the total difference in alveolar bone density on the buccal cortical (BC), cancellous (C), and palatal cortical (PC) bones over a period of 3 months

\section{Discussion}

Many studies have tried to increase the rate of tooth movement such as altering force magnitude, ${ }^{13}$ vitamin D metabolite injection, modifying bone metabolism by parathyroid hormone (PTH), steroid therapy, and thyroxin intervention. ${ }^{14}$ To rule out the confounding effects on tooth movement, a split mouth design was undertaken. Acetaminophen was advised as analgesic since studies have shown that acetaminophen did not affect OTM..$^{15}$ The volume and method of periodontal injection was performed as recommended by Walton and Abott; Malamed. ${ }^{16}$ The in situ gel form of drug delivery system provided accurate dose at the site of action and prolonged the duration of drug action. Plain gel was given in the control side to rule out its side effects on OTM. The rationale behind choosing this dose was attributed to previous report ${ }^{9}$ about calcitriol on bone remodeling. The human equivalent dose (HED) conversion was done for a dosage of $50 \mathrm{pg} / \mathrm{mL}$ using the formula as described by Sharma and McNeill. ${ }^{17}$

In the first month, as shown in Table 1, the rate of canine movement was faster on the experimental side; however, it was statistically insignificant when compared to the control side. During second and third months, there was faster rate of canine movement on experimental side, which was statistically significant. The finding was in accordance with previous study ${ }^{9}$ that after 21 days of canine retraction with a light-wire retraction spring, the teeth that had moved $60 \%$ further than matched control teeth $(p<0.05)$. When compared between second to third months, there was more rate of canine movement in the second month than third month as maximum amount of canine distalization on the experimental side occurred in the second month, as shown in Figure 3, as there was not much space remaining to be moved in the third month for majority of participants. During each month, the experimental side showed clinically higher rate of canine movement compared to the control side. This finding comes in agreement with previous study ${ }^{9}$ which indicated that the effect of calcitriol on OTM is highest when administered in doses relatively equivalent to the normal physiologic level.

As shown in Table 2 and Figure 4, there was a mean anchorage loss of $0.60 \pm 0.27 \mathrm{~mm}$, which was statistically insignificant on both experimental side and control side. This could be due to application of optimum orthodontic force $(150 \mathrm{~g})$ and proper anchorage preparations, as reported by Storey and Smith; Bohl et al., and Boester and Johnston. ${ }^{18}$

Multi-slice spiral computed tomography was preferred over cone beam computed tomography $(\mathrm{CBCT})$ as it was more accurate in differentiation of structures within approximately $1 \mathrm{HU} .^{19}$ The results (Table 5 and Fig. 5) showed a reduction in bone density on buccal cortical bone (mean-7.33 HU) on the experimental side and $6.00 \mathrm{HU}$ on the control side, which was statistically insignificant. 
There was a reduction in the alveolar bone density on the palatal cortical bone (mean-5.40 HU) on experimental side and $4.86 \mathrm{HU}$ on the control side, which was also statistically insignificant. There was a statistically significant reduction in the cancellous bone density (mean-19.93 HU) on the experimental side; however on the control side, there was a reduction in the cancellous bone density (mean-7.53 HU), which was statistically insignificant. A probable explanation might be due to the progenitors that exist within the hematopoietic cells that may easily reach trabecular and endosteal sites, in the bone marrow side. But in the alveolar side, the progenitors may either be recruited from the circulation or be preexisting in the periodontal ligament. It was also seen that remodeling is more frequent in trabecular bone than in cortical bone. ${ }^{20}$ This phenomenon could have been accelerated on the experimental side due to $1,25 \mathrm{DHC}$.

There was statistically significant reduction in the overall bone density on both experimental and control sides, as shown in Tables 4 and 5. This can be correlated with the previous findings described by Hsu et al. and Melsen that during OTM there is generalized reduction in alveolar bone density. In this study, bone density around the teeth is reduced by $20-30 \%$, which probably indicates that the teeth were moved in the stage of "through bone." 21

Mandall et al. suggested that 12-week reduction in treatment time from average time is clinically significant in terms of efficiency. ${ }^{22}$ OTM is subjected to individual variations so the generalization of the study and results are limited. Factors such as patient's age, brushing technique, dietary habits, and quality of dental extractions can be considered as few potential sources of bias that may affect the rate of canine distalization. In this clinical trial, it seems possible to translate the results into clinical benefits. It has also been able to highlight the scope of local administration of vitamin D in accelerating tooth movement in a biological manner than other approaches.

\section{Conclusion}

- There is a significant increase in the amount of canine distalization with a local administration of 1,25 DHC.

- In situ gel of 1,25 DHC is a novel method of local drug delivery system to accelerate OTM.

- There is no significant difference in the amount of anchorage loss with or without the local administration of 1,25 DHC.

- There is significant reduction in the cancellous bone density with a local administration of 1,25 DHC.

- There is also a significant reduction in the overall bone density at buccal and palatal cortical bones during OTM, with or without a local administration of 1,25 DHC.

\section{References}

1. Gameiro GH, Pereira-Neto JS, Magnani MB, et al. The influence of drugs and systemic factors on orthodontic tooth movement. J Clin Orthod 2007;41(2):73-78.

2. Krishnan V, Davidovitch Z. Cellular, molecular, and tissue level reactions to orthodontic force. Am J Orthod Dentofacial Orthop 2006;129(4):469.e1-469.e32. DOI: 10.1016/j.ajodo.2005.10.007.

3. Masella RS, Meister M. Current concepts in the biology of orthodontic tooth movement. Am J Orthod Dentofacial Orthop 2006;129(4): 458-468. DOI: 10.1016/j.ajodo.2005.12.013.
4. Kale S, Kocadereli I, Atilla P, et al. Comparison of the effects of 1,25 dihydroxycholecalciferol and prostaglandin E2 on orthodontic tooth movement. Am J Orthod Dentofacial Orthop 2004;125(5):607-614. DOI: 10.1016/j.ajodo.2003.06.002.

5. Yamasaki K, Shibata $Y$, Imai $S$, et al. Clinical application of prostaglandin E1 (PGE1) upon orthodontic tooth movement. Am J Orthod 1984;85(6):508-518. DOI: 10.1016/0002-9416(84)90091-5.

6. Stark M, Sinclair PM. Effect of pulsed electromagnetic fields on orthodontic tooth movement. Am J Orthod Dentofacial Orthop 1987;91(2):91-104. DOI: 10.1016/0889-5406(87)90465-3.

7. Saito M, Saito S, Ngan PW, et al. Interleukin 1 beta and prostaglandin $E$ are involved in the response of periodontal cells to mechanical stress in vivo and in vitro. Am J Orthod Dentofacial Orthop 1991;99(3): 226-240. DOI: 10.1016/0889-5406(91)70005-H.

8. Leiker BJ, Nanda RS, Currier GF, et al. The effects of exogenous prostaglandins on orthodontic tooth movement in rats. Am J Orthod Dentofacial Orthop 1995;108(4):380-388. DOI: 10.1016/s08895406(95)70035-8.

9. Collins MK, Sinclair PM. The local use of vitamin D to increase the rate of orthodontic tooth movement. Am J Orthod Dentofacial Orthop 1988;94(4):278-284. DOI: 10.1016/0889-5406(88)90052-2.

10. Katsumata A, Hirukawa A, Okumura $S$, et al. Relationship between density variability and imaging volume size in cone-beam computerized tomographic scanning of the maxillofacial region: an in vitro study. Oral Surg Oral Med Oral Pathol Oral Radiol Endod 2009;107(3):420-425. DOI: 10.1016/j.tripleo.2008.05.049.

11. Hoggan BR, Sadowsky C. The use of palatal rugae for the assessment of antero posterior tooth movements. Am J Orthod Dentofacial Orthop 2001;119(5):482-488. DOI: 10.1067/mod.2001.113001.

12. Park HS, Lee YJ, Jeong SH, et al. Density of the alveolar and basal bones of the maxilla and the mandible. Am J Orthod Dentofacial Orthop 2008;133(1):30-37. DOI: 10.1016/j.ajodo.2006.01.044.

13. Furstman L, Bernick S, Aldrich DA. Differential response incident to tooth movement. Am J Orthod 1971;59(6):600-608. DOI: 10.1016/0002-9416(71)90007-8.

14. Diravidamani K, Sivalingam SK, Agarwal V. Drugs influencing orthodontic tooth movement: an overall review. J Pharm Bioallied Sci 2012;4(Suppl 2):S299-S303. DOI: 10.4103/0975-7406.100278.

15. Bartzela T, Türp JC, Motschall E, et al. Medication effects on the rate of orthodontic tooth movement: a systematic literature review. Am J Orthod Dentofacial Orthop 2009;135(1):16-26. DOI: 10.1016/ j.ajodo.2008.08.016.

16. Malamed SF. The periodontal ligament (PDL) injection: an alternative to inferior alveolar nerve block. Oral Surg Oral Med Oral Pathol 1982;53(2):117-121. DOI: 10.1016/0030-4220(82)90273-0.

17. Sharma $\mathrm{V}, \mathrm{McNeill} \mathrm{JH}$. To scale or not to scale: the principles of dose extrapolation. Br J Pharmacol 2009;157(6):907-921. DOI: 10.1111/j.1476-5381.2009.00267.x.

18. Boester $\mathrm{CH}$, Johnston $\mathrm{LE}$. A clinical investigation of the concepts of differential and optimal force in canine retraction. Angle Orthod 1974;44(2):113-119. DOI: 10.1043/0003-3219(1974)044<0113:ACIOTC $>2.0 . \mathrm{CO} ; 2$.

19. Shin HO, Falck CV, Galanski M. Low-contrast detectability in volume rendering: a phantom study on multidetector-row spiral CT data. Eur Radiol 2004;14(2):341-349. DOI: 10.1007/s00330-003-2084-4.

20. Lerner UH. Osteoblasts, osteoclasts, and osteocytes: unveiling their intimate-associated responses to applied orthodontic forces. Semin Orthod 2012;18:237-248.

21. Hsu JT, Chang HW, Huang HL, et al. Bone-density changes around teeth during orthodontic treatment. Clin Oral Investig 2011;15(4): 511-519. DOI: 10.1007/s00784-010-0410-1.

22. Mandall NA, Lowe C, Worthington HV, et al. Which orthodontic arch-wire sequence? A randomized clinical trial. Eur J Orthod 2006;28(6):561-566. DOI: 10.1093/ejo/cjl030. 